УДК 332.02

$10.17213 / 2075-2067-2021-4-181-187$

\title{
ОРГАНИЗАЦИОННО-ЭКОНОМИЧЕСКИЕ ОСНОВЫ КОНТРОЛЛИНГА КАК МЕТОДА РЕГУЛИРОВАНИЯ ПРИРОДОПОЛЬЗОВАНИЯ
}

\author{
(C) 2021 г. В. Ф. Савцук, Е. В. Романенко
}
Южно-Российский государственный политехнический университет (НПИ) имени М. И. Платова, г. Новочеркасск, Россия

Цель исследования. Представить органическое соединение организационных экономических основ контроллинга, информачионно-ресурсное взаимодействие элементов системы контроллинга в промымленных организациях как метод регулирования природопользования.

Методологической основой исследования организационно-экономических основ контроллинга природопользования является диалектический материализм - всеобщая теория познания объективного мира. Диалектический метод означает, что взаимодействие общества и природы рассматривается с точки зрения их всеобщей связи, перехода количественных изменений в качественное, раскрытия внутренних противоречий. Подходит к изучаемым явлениям и исторически рассматривает их в движении, изменении и развитии.

Результаты исследования: закономерный метод регулирования природопользования.

Ключевые слова: эффекты природопользования; производственная инфраструктура; конкурентоспособная перспектива; лимиты использования природных ресурсов; энергосберегающие проекты; ресурсосберегающие технологии; воспроизводство природных ресурсов; научно-технический потенциал общества.

\section{ORGANIZATIONAL AND ECONOMIC BASES OF CONTROLLING AS A METHOD OF ENVIRONMENTAL MANAGEMENT REGULATION}

\author{
(C) 2021 V. F. Savchuk, E. V. Romanenko
}

\section{Platov South Russian State Polytechnic University (NPI), Novocherkassk, Russia}

The purpose of the study. To present the organic connection of the organizational and economic foundations of controlling, the information and resource interaction of the elements of the controlling system in industrial organizations as a method of regulating environmental management.

The methodological basis for the study of the organizational and economic foundations of controlling nature management is dialectical materialism - a universal theory of knowledge of the objective world. The dialectical method means that the interaction of society and nature is considered from the point of view of their universal connection, the transition of quantitative changes to qualitative changes, the disclosure of internal contradictions. Approaches the phenomena under study and historically considers them in motion, change, and development.

The results of the study: natural resource management regulation method. 
Key words: environmental management effects; production infrastructure; competitive perspective; limits of natural resources use; energy-saving projects; resource-saving technologies; natural resources reproduction; scientific and technical potential of the society.

Введение. Новый характер государственного воздействия на ускорение научно-технического прогресса отмечает возрастающую роль не директивных рычагов влияния на экономику, а контролирующих и регулирующих функций государства, направленных на стимулирование решения важнейших с точки зрения перспективы научно-технических задач и сдерживания тех действий, которые могут иметь нежелательные эффекты природопользования. Методы косвенного воздействия, осуществляемые через налоговую, кредитно-финансовую, амортизационную, внешнеэкономическую политику, должны реализоваться в трех основных формах: субсидии, контракты, индивидуальные соглашения.

Становятся эффективными специальные меры поощрения, которые прямо направлены на стимулирование с помощью налоговых или других законодательных льгот тех или иных фирм и организаций. К указанным мерам поощрения можно отнести гарантии государства по финансированию рисковых проектов, стимулирование конкретных исследований с внешними фирмами, льготы на капитальные вложения для реализации отдельных энергосберегающих проектов, ускоренную амортизацию оборудования природоохранного назначения и др.

В РФ наибольшее значение приобретают следующие направления научно-технического прогресса:

- поддержание и обновление материально-технической базы отраслей социальной и производственной инфраструктуры;

- сохранение ресурсного потенциала, повышение эффективности его создания и использования;

- решение глобальных вопросов контроллинга природоохранными мероприятиями по выживанию общества и реализации инвестиционных проектов в региональном природопользовании;

- прогнозирование отдельных последствий внедрения достижений научно-технического прогресса;
- поддержание и стимулирование тех исследований, которые обещают конкурентоспособную перспективу;

- насыщение рынка товарами, основой которых являются отечественные достижения;

- реализация политики рационального использования природных и трудовых ресурсов;

- меры законодательного характера, касающиеся возрастающей роли государственного регулирования рыночной системы отношений в обществе.

Основная причина неэффективного применения природного потенциала во многом сводится к отсутствию научно обоснованной экономической оценки и определения ценности каждого вида природных ресурсов.

Несовершенство механизма экономики природопользования явилось «аргументом» для массовой закупки импортного малоотходного прогрессивного оборудования. Ввоз техники и технологии из-за рубежа не сдвинул научно-технический прогресс в российском народно-хозяйственном комплексе по причине неумелого обращения (низкого качества рабочей силы) и отсутствия материальной и социальной заинтересованности в ее рациональном применении.

Цели развития российского общества должны соответствовать критериям эффективного природопользования, что требует принципиально новых методологических разработок методики оценки «фонда» прошлого загрязнения, текущего ущерба природопользования и величины расходов на оптимальное воспроизводство использованных элементов окружающей среды.

Прежде всего, следует выяснить направления, источники и характер мероприятий, направленных на цели природопользования. Изучив источники, направления, структуру затрат по их формированию, логично перейти к рассмотрению вопросов эффективности и результативности природоохранных средств. Соотношение затрат с результатами может дать общую картину эффективности природоохранной деятельности в каких-то количественных и качественных показателях. 
В законе Российской Федерации «Об охране окружающей природной среды» [7] указываются основные задачи экономического механизма природопользования, а именно:

— планирование и финансирование природоохранных мероприятий;

- установление лимитов использования природных ресурсов, выбросов и сбросов загрязняющих веществ в окружающую среду и размещение отходов;

- установление нормативов платы и размеров платежей за использование природных ресурсов, выбросы и сбросы загрязняющих веществ в окружающую природную среду, размещение отходов и другие виды веществ вредного воздействия;

- предоставление предприятиям, учреждениям и организациям, а также гражданам налоговых, кредитных и иных льгот при внедрении ими малоотходных и ресурсосберегающих технологий и нетрадиционных видов энергии, осуществление других эффективных мер по контроллингу программ природопользования;

— возмещение в установленном порядке вреда, причиненного природным ресурсам и здоровью человека.

По мере ускорения научно-технического прогресса во всем мире стал наблюдаться рост технологического и социального отчуждения человека. Негативные последствия НТП и НТР можно объединить в две проблемы:

1) вопросы усиления урбанизации и как следствие - отчуждение человека от человека;

2) отчуждение человека от природы, а значит, и от родовой сущности субъекта. Мало кто сегодня будет возражать против того, что современные крупные, средние и даже малые города (это касается России) в разной степени могут служить благоприятной экологической «нишей» для существования и всестороннего развития людей как личностей. В этом смысле можно говорить о том, что город во многом «античеловечен», «антигуманен».

Не покидая позиции диалектической логики, присутствие форм отчуждения можно объяснить лишь какими-то общими законами развития общества. Очевидно, что природная среда развивается по своим биологохимическим и физическим законам, а технологический способ производства каждой формации тесно связан и вытекает из законов развития самой природной среды, поэтому элементы отчуждения и эксплуатации присутствуют в любом обществе, другое дело - их мера, специфический характер и формы проявления. Если мы принимаем как данную объективность, что предпосылками эксплуатации индивидов является отчуждение их от природы, от собственности и от власти, то следует четко различать предпосылки и причины социально-экономического неравенства в обществе. Главной предпосылкой и условием научно-технического прогресса на первых этапах становления цивилизации служило определенное качество и количество природных ресурсов и самой окружающей природной среды. По мере «автономизации» человеческой жизнедеятельности, повышения благосостояния людей наметились, по крайней мере, пять направлений отчуждения человека, и исторически это привело к появлению частной собственности. Частная собственность и отчуждение могут существовать и развиваться только в условиях наемного труда, объектами которого могут быть и природа и государство, и представители определенных слоев общества и сам субъект. По мере ускорения НТП и развертывания научно-технической революции по самым разным направлениям самоотчуждение и труд по найму как некие феномены и явления объективной действительности все в большей мере поддаются осмысливанию и требуют дальнейшего политико-экономического изучения.

Производство можно определить как взаимодействие общества с природой, как воздействие трудовых ресурсов (совокупного работника) на систему ресурсов природы, выступающих в производстве в качестве предметов и средств труда. Поэтому целеполагающие функции главного элемента производительных сил человека и функции природных элементов (в одном случае элементов средств производства) совпадают, так как имеют конечной целью расширенное воспроизводство материальных и духовных благ. Природные ресурсы, вне зависимости от воздействия общества с его научно-техническим потенциалом, постоянно стремятся к самосохранению и равновесному динамическому изменению. 
Работник составляет более активную сторону взаимодействия, а поэтому оказывается всегда определяющим в смысле получения позитивного результата. Мера единства и отчуждения человека от природы зависит от уровня компетентного вмешательства в природную среду и от применяемых средств и методов достижения своих целей. Прежде чем приступить к взаимодействию с природными условиями, к потреблению природных ресурсов, любой субъект пытается спрогнозировать результаты своей деятельности, для чего составляются тактические и стратегические планы-прогнозы.

Любой ущерб, нанесенный природе, отражается на ухудшении социального и экономического благосостояния людей. Государственные мероприятия по освоению природных ресурсов оказались не только неэффективными, но и нанесли непоправимый удар по жизнедеятельности населения тех территорий, где проводилось такое освоение. Государство выступало в роли временщика, от имени которого хищнически эксплуатировались природные ресурсы, составляющие основу природной среды. На самом деле у природных ресурсов подлинного хозяина не было никогда, как и не было ответственного за причиненные природе многочисленные беды. В основе экономической справедливости и свободы лежат отношения собственности, и пределы реализации этих категорий находятся внутри феномена отчуждения человека от природы и самореализации его как личности.

Важное место в рыночной системе занимают рынок рабочей силы и рынок природных ресурсов. Рыночные отношения приводят к расслоению общества и экономическому неравенству, но такое неравенство следует считать справедливым. Следует подчеркнуть, что рабочая сила в рыночных условиях приобрела закономерную роль специфического товара, в качестве которого выполняет двойственные функции, обусловленные двойственным характером труда и производства. Такое понимание функций рабочей силы в качестве товара и оплаты по ее потребительной стоимости не противоречит положению о заработной плате как превращенной форме стоимости и цены рабочей силы в рыночном хозяйстве.
Если воспроизводство рабочей силы по еe стоимости (зарплата) определяется общественно необходимыми затратами на производство потребляемых рабочими благ, то сами эти затраты (сколько нужно труда на их производство) определяются уже не стоимостью, а потребительной стоимостью жизненных благ:

1) планирование ресурсов - разработка плана удовлетворения будущих потребителей в людских ресурсах;

2) набор персонала - создание резерва потенциальных кандидатов по всем должностям;

3) отбор - оценка кандидатов на рабочие места и отбор лучших из резерва, созданного в ходе набора;

4) определение заработной платы и льгот - разработка структуры заработной платы и льгот в целях привлечения, найма и сохранения служащих;

5) профориентация и адаптация - введение нанятых работников в организацию и ее подразделения, развитие у работников понимания того, что ожидает от него организация и какой труд получает заслуженную оценку;

6) обучение - разработка программ для обучения трудовым навыкам, требующимся для эффективного выполнения работы;

7) оценка трудовой деятельности - разработка методик оценки трудовой деятельности и доведение их до работника;

8) повышение, понижение, перевод, увольнение - разработка методов перемещения работников с большей или меньшей ответственностью, развитие их профессионального опыта путем перемещения на другие должности или участки работы, а также процедуры прекращения договора найма;

9) подготовка руководящих кадров, управление продвижением по службе, разработка программ, направленных на развитие собственностей и повышение эффективности труда руководящих кадров.

Величина затрат по воспроизводству природных ресурсов может равняться величине экономической оценки или цене потребительной стоимости этих ресурсов, а величина заработной платы по минимуму может определяться величиной стоимости рабочей силы, а по максимуму она соответствует потребительной стоимости товара рабочей силы, ее совокупной полезности. 
Для решения данного вопроса необходимо, во-первых, потребительную (полезную) стоимость продукта выразить количеством замещаемого, сэкономленного живого труда с вычетом затрат труда на достигаемый объем экономии (замещения). Во-вторых, необходимо привести таким образом измеренную производительную силу труда (в единицах сэкономленного труда) в потребительную силу труда, т.е. определить в итоге потребительную стоимость рабочей силы. Она будет измеряться тем количеством сэкономленного рабочего времени, которое становится как мерой получения благосостояния сверх минимума жизненных средств, так и мерой развития работника. Распределить жизненные средства на основе сэкономленного труда, достигаемого за счет более высокой потребительной стоимости рабочей силы, можно столь же успешно, как и на основе затраченного труда. Функционально-целевая взаимосвязь трудовых и природных ресурсов свидетельствует о необходимости нового методологического подхода к анализу экономических процессов, протекающих в рамках способа производства и формации.

С точки зрения генезиса любого производства, требуется выяснить, какова система и характер соединения работника со средствами производства. Выявление роли, места и функций влияния человека на природную среду не может происходить без аналитической работы по выяснению сущности природного фактора и его обратного воздействия на производство. После этого можно установить и смоделировать закономерности, законы движения системы «человек - природа», «экономический человек», «природные ресурсы», «научно-технический потенциал общества», «отношения природопользования», зависящие в том числе от качества природной окружающей среды. Необходимо отметить, что работника без природной среды не бывает, в то время как природа сама по себе самодостаточна и может функционировать без человека и общества.

Отсюда следует, что природные ресурсы не всегда остаются объективным фактором, от которого зависят благополучие и мера экономической самостоятельности субъектов воздействия. Первичность окружающей природной среды приводит нас к той истине, что сохраняя и воспроизводя природные ресурсы, мы тем самым сохраняем и воспроизводим себя, создавая необходимые условия самовоспроизводства и экономического благосостояния. Рыночный режим воспроизводства позволяет интенсифицировать экономику, а более совершенные товарно-денежные отношения заставят общество как совокупное единство разных форм собственников развивать экономику по антизатратному направлению - единственному пути, который не противоречит законам самой природы.

Необходимо обратить внимание на проблему их потребительной стоимости. Стоимость рабочей силы включает в себя весь живой труд за вычетом фонда, отчисляемого в госбюджет и расходуемого затем на общие цели государства и общества. В понятие «потребительная стоимость рабочей силы» следует включать весь потребительный продукт, созданный конкретным и абстрактным трудом, ведь (овеществленный) труд - это тоже когда-то израсходованный труд, затраченный на производство средств производства. Заработная плата, как известно, составляет лишь часть необходимого и прибавочного продукта и представляет собой в этом виде превращенную форму стоимости и цены рабочей силы, но следует понять, что она должна быть равна по величине необходимому продукту.

Кроме того, издержки производства и прибавочный продукт в сумме должны составлять потенциальный фонд потребления совокупного работника, включая и работников непроизводственной сферы. Издержки производства и издержки обращения составляют полную себестоимость продукции для общества и включают в себя потребительную часть средств производства и обращения, номинальная зарплата как денежное выражение части издержек не может быть меньше величины расходов на нормальное (в соответствии со средними в данном обществе условиями жизнедеятельности) воспроизводство рабочей силы.

Следовательно, в совокупных издержках общества отражаются затраты предметов труда (природных ресурсов), средств труда (технологических овеществленных машин и оборудования) и живого труда. Таким образом, можно говорить о трех видах затрат на воспроизводство составных частей общих издержек. 
Общим у трудовых и природных ресурсов является то, что они выступают на рынке в качестве специфических товаров и требуют для своего восстановления затрат в особых формах. Например, базой экономической оценки и цены для воспроизводства ресурсов природы необходимо считать среднюю величину расходов на их воспроизводство, т.е. величину затрат на воспроизводство единицы ресурса. Цена труда и цена природного ресурса на рынке труда и рынке средств производства зависит в первую очередь от спроса и предложения, но рыночная цена согласно закону стоимости в конечном счете должна соответствовать совокупным затратам на их поддержание или воспроизводство.

Заключение. Маятник рыночной цены и стоимости может колебаться вокруг издержек на их сохранение и стимулировать повышение качества рабочей силы, а также предметов труда. Только при органическом включении работника в систему производства, его добровольном желании рачительно использовать материальные, финансовые, природные ресурсы и создании системы контроллинга природопользования мы получим сбалансированную экономику.

\section{Литература}

1. О недропользовании на территории Ростовской области: обл. закон Ростовской области от 25.10.2002 г. №275-3С.

2. Об охране окружающей среды: Федеральный закон Российской Федерации.

3. Красе М.C. Моделирование экологоэкономических систем. - М.: ИНФРА-М, 2012.

4. Папенов К.В. Экономика природопользования: Курс лекций. Ч. II. - М., 2004.

5. Экономика природопользования / под ред. К. В. Папенова. - М., 2006.

6. Анопченко Т.Ю., Маколова Л.В. Проблема формирования механизма рационального использования ресурсов в агропромышленном комплексе с учетом экологических приоритетов // Вестник Самарского государственного экономического университета. 2013. - №110. - С. 108-112.

7. Закон Российской Федерации «Об охране окружающей природной среды» [Электронный ресурс]. - Режим доступа: http:// www.kremlin.ru/acts/bank.

\section{References}

1. O nedropol'zovanii na territorii Rostovskoj oblasti: obl. zakon Rostovskoj oblasti ot 25.10.2002 g. №275-ZS [On subsurface use in the territory of the Rostov region: regional Law of the Rostov region №275-ZS of 25.10.2002].

2. $\mathrm{Ob}$ ohrane okruzhajushhej sredy: Federal'nyj zakon Rossijskoj Federacii [On environmental protection: Federal Law of the Russian Federation].

3. Krase M.S. Modelirovanie jekologo-jekonomicheskih sistem [Modeling of ecological and economic systems]. - Moscow: INFRA-M, 2012.

4. Papenov K. V. Jekonomika prirodopol'zovanija: Kurs lekcij [Economics of environmental management: A course of lectures]. Part II. - Moscow, 2004.

5. Jekonomika prirodopol'zovanija / pod red. K. V. Papenova [Economics of environmental management / In K. V. Papenov (eds.)]. Moscow, 2006.

6. Anopchenko T. Ju., Makolova L.V. Problema formirovanija mehanizma racional'nogo ispol'zovanija resursov $\mathrm{v}$ agropromyshlennom komplekse $\mathrm{s}$ uchetom jekologicheskih prioritetov [The problem of forming a mechanism for rational use of resources in the agro-industrial complex taking into account environmental priorities] // Vestnik Samarskogo gosudarstvennogo jekonomicheskogo universiteta [Bulletin of the Samara State University of Economics]. 2013. — №110. — Pp. 108-112.

7. Zakon Rossijskoj Federacii «Ob ohrane okruzhajushhej prirodnoj sredy» [The Law of the Russian Federation «On environmental protection»] [Jelektronnyj resurs]. — URL: http:// www.kremlin.ru/acts/bank. 


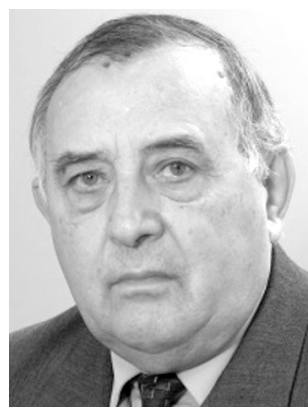

Савчук Владимир Федорович - доцент, кандидат экономических наук, доцент кафедры «Социальные и гуманитарные науки» Южно-Российского государственного политехнического университета (НПИ) имени М.И. Платова.

Savchuk Vladimir Fedorovich - Associate Professor, Candidate of Economic Sciences, Associate Professor of the «Social and Humanitarian Sciences» Department, Platov South Russian State Polytechnic University (NPI).

346428 , г. Новочеркасск, ул. Просвещения, 132

132 Prosveshcheniya st., 346428, Novocherkassk, Russia

E-mail:smm-nauka@yandex.ru

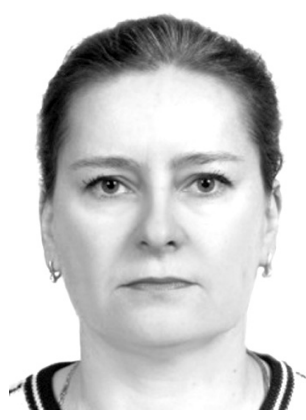

Романенко Елена Валерьевна - старший преподаватель кафедры «Производственный и инновационный менеджмент» Южно-Российского государственного политехнического университета (НПИ).

Romanenko Elena Valeryevna - Senior Lecturer of the Department «Production and Innovation Management», South-Russian State Polytechnic University (NPI).

346428 , г. Новочеркасск, ул. Просвещения, 132

132 Prosveshcheniya st., 346428, Novocherkassk, Russia

E-mail: levchenckona@yandex.ru 